\title{
Identification and Characterization of Tyrosylprotein Sulfotransferase from Human Saliva
}

\author{
C. Kasinathan 1 , P. Ramaprasad ${ }^{1}$ and P. Sundaram ${ }^{2}$ \\ 1. Oral Biology, NJ Dental School, University of Medicine and Dentistry of New Jersey, Newark, NJ 07103-2400, USA. \\ 2. Recombinant Technologies LLC, 5 Science Park at Yale, New Haven, CT 06511, USA.
}

Corresponding address: Dr. C. Kasinathan, Oral Biology, NJ Dental School, University of Medicine and Dentistry of New Jersey, 110 Bergen Street, Newark, NJ 07103-2400, USA. Tel: 973-972-7426 kasinach@umdnj.edu

Received: 2005.09.20; Accepted: 2005.10.12; Published: 2005.10.12

Tyrosylprotein sulfotransferase (TPST), the enzyme responsible for the sulfation of tyrosine residues, has been identified and characterized in submandibular salivary glands previously (William et al. Arch Biochem Biophys 338: 90-96). Tyrosylprotein sulfotransferase catalyses the sulfation of a variety of secretory and membrane proteins and is believed to be present only in the cell. In the present study, this enzyme was identified for the first time in human saliva. Analysis of human saliva and parotid saliva for the presence of tyrosylprotein sulfotransferase revealed tyrosine sulfating activity displayed by both whole saliva and parotid saliva at $\mathrm{pH}$ optimum of 6.8. In contrast to tyrosylprotein sulfotransferase isolated from submandibular salivary glands, salivary enzyme does not require the presence of Triton $\mathrm{X}-100, \mathrm{NaF}$ and 5'AMP for maximal activity. Similar to the submandibular TPST, the enzyme from saliva also required $\mathrm{MnCl}_{2}$ for its activity. Maximum TPST activity was observed at $20 \mathrm{mM} \mathrm{MnCl}_{2}$. The enzyme from saliva was immunoprecipitated and purified by immunoaffinity column using anti-TPST antibody. Affinity purified salivary TPST showed a single band of 50-54 kDa. This study is the first report characterizing a tyrosylprotein sulfotransferase in a secretory fluid.

K ey words: Tyrosylprotein sulfotransferase, human saliva, Purification, A ffinity Chromatography, A nti- tyrosylprotein sulfotransferase antibody

\section{Introduction}

Tyrosine sulfation, a posttranslational modification involved in the processing of secretory proteins, is the covalent attachment of sulfate to the hydroxyl group of the tyrosyl residues in peptides and proteins. O-sulfation of the tyrosine residues has been the subject of several studies on the posttranslational modification of proteins [2]. This modification occurs in the trans-Golgi, the compartment involved in the maturation and sorting of secretory proteins and peptides including cholecystokinin [3], fibrinopeptide B [4], gastrin [5] phyllokinin [6], leucosulfakinin [7], C4 complement [8], hirudin [9], Pselectin glycoprotein ligand-1 (PSGL-1) [10] and chemokine receptor CCR5 [11]. Tyrosine sulfation in these proteins has been suggested to be essential for their biological activity, half-life, and secretion. Sulfation of tyrosyl residues in cholecystokinin is required for its optimal biological activity [12] and in the case of hirudin, tyrosine sulfation increases the binding efficiency to thrombin [9]. In M31 hybridoma cell line, tyrosine sulfation has been shown to serve as a signal for the secretion of IgG [13]. In PSGL-1, tyrosine sulfation is required for its binding to p-selectin [10] and the tyrosine sulfation of CCR5 facilitates HIV-1 entry [11]. Although the significance of tyrosine sulfation in these and several other proteins has been studied in detail, its role in salivary protein is yet to be investigated.

Tyrosylprotein sulfotransferase has been identified in numerous tissues including bovine adrenal medulla [14], rat liver [15], brain [16], gastric mucosa [17], submandibular salivary glands [18] and platelets [19]. In this study, we demonstrate for the first time the detection, isolation and characterization of TPST from human saliva.

\section{Materials and methods}

\section{Materials}

[35S]PAPS (2 Ci/mmol) was from DuPont New England Nuclear, EAY (Mr $47 \mathrm{kDa})$, 5'-AMP were from Sigma-Aldrich. All other reagents were of analytical grade.

\section{Collection of Saliva}

Human Saliva

Unstimulated saliva was obtained from healthy individuals. The saliva was centrifuged at 6,000 RPM for $30 \mathrm{~min}$ and the clear supernatant was separated from sediment containing food particles.

\section{Parotid Saliva}

Parotid saliva was collected as described in [20]. Parotid salivary flow was stimulated by means of confectionary which contained citric acid and tartaric acid. The saliva sample of about $10 \mathrm{ml}$ was collected from parotid salivary glands by means of special devices. Protein concentration was estimated by the BCA protein assay reagent kit (Pierce chemical Co). Optimally diluted saliva samples were used for the tyrosylprotein sulfotransferase activity.

\section{Assay of tyrosylprotein sulfotransferase}

The tyrosylprotein sulfotransferase assay mixture contained the following components: acceptor, unsulfated EAY at concentrations indicated in text, $5 \mu \mathrm{M}$ [35S]PAPS

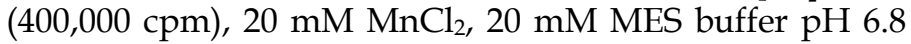
and saliva ( $50 \mu \mathrm{g}$ protein) in a final volume of $50 \mu \mathrm{l}$. Assays were initiated by the addition of the enzyme and incubated for $30 \mathrm{~min}$ at $37^{\circ} \mathrm{C}$. The reactions were stopped 
by spotting $35 \mu \mathrm{l}$ aliquot of the reaction mixture on a $2.4 \mathrm{x}$ $2.4 \mathrm{~cm}$ Whatman No. 3MM filter paper [15]. The papers were washed three times for $15 \mathrm{~min}$ in $10 \%$ trichloroacetic acid/10 $\mathrm{mM} \mathrm{Na}_{2} \mathrm{SO}_{4}$ and rinsed $5 \mathrm{~min}$ in $95 \%$ ethanol. The dried papers were placed in vials containing scintillation solution and counted in a TriCarb-1500 scintillation counter.

\section{SDS-Polyacrylamide Gel Electrophoresis}

Proteins were separated by electrophoresis by the method of Laemml [21]. The separating gels contained $10 \%(\mathrm{w} / \mathrm{v})$ acrylamide, bis(acrylamide) in the ratio of $37.5: 1,0.375$ M Tris-HCl, pH 8.8, 0.1\% SDS, $0.026 \%$ TEMED, and $0.026 \%$ ammonium persulfate. The stacking gel contained 3\% acrylamide, bis(acrylamide) in the same ratio as before, $0.125 \mathrm{M}$ Tris- $\mathrm{HCl}, \mathrm{pH} 6.8,0.1 \% \mathrm{SDS}, 0.05 \%$ ammonium persulfate, and $0.4 \%$ TEMED. Electrophoresis was performed in a Mighty Small gel apparatus (Hoefer Scientific Instruments, San Francisco, CA) at $4^{\circ} \mathrm{C}$ at a constant current of $20 \mathrm{~mA}$ per gel for approximately $1 \mathrm{~h}$. Protein bands on the gels were visualized by silver staining.

\section{Immunoblot Procedure}

Proteins were resolved by SDS-PAGE on a $10 \%$ polyacrylamide gel and electrophoretically transferred (20 $\mathrm{V}$ for $20 \mathrm{~min}$ ) to a nitrocellulose membrane (Millipore) by means of a Bio-Rad Semi Dry Transblot apparatus according to the procedure supplied by the Bio-Rad. The section of the nitrocellulose membrane containing the molecular weight standards was cut off and stained with Ponceau $S$ in $45 \%$ methanol and $10 \%$ acetic acid and destained in water. The membrane was blocked overnight at $4^{\circ} \mathrm{C}$ with bovine serum albumin $(3 \% \mathrm{w} / \mathrm{v})$. The blot was washed with Tris buffered saline ( $25 \mathrm{mM}, \mathrm{pH}$ 8.0) containing $0.05 \%$ Tween 20 and $0.1 \%$ BSA and incubated with IgG fraction of rabbit anti TPST antibody for an hour at room temperature. After washing the blot with wash buffer, the membrane was further incubated with alkaline phosphatase conjugated goat anti-rabbit immunoglobulin G (1:5000) for an hour. The substrate for alkaline phosphatase was consisted of the p-nitro blue tetrazolium and 5-bromo-4-chloro-3-indolyl phosphate.

\section{Immunoprecipitation}

Immunoprecipitation of the TPST present in saliva was carried out in $1.5 \mathrm{ml}$ microcentrifuge tubes using TPST antibody, as described in [1]. Briefly, different concentrations of immune and preimmune sera (1:1000 dilution) were added to $100 \mu \mathrm{l}$ of saliva and the mixture was incubated at room temperature for $4 \mathrm{~h}$. After incubation, $30 \mu \mathrm{l}$ of Protein A sepharose $(25 \%)$ was added. Following overnight agitation at $4^{\circ} \mathrm{C}$, Protein A sepharose beads bound to antigen-antibody complexes were pelleted by centrifugation and the supernatant was used for TPST assay.

\section{Purification of tyrosylprotein Sulfotransferase from saliva by Immuno affinity Chromatography}

The IgG fraction of rabbit anti-TPST was coupled to $\mathrm{CNBr}$-activated Sepharose 4B beads. About $75 \mathrm{mg}$ of IgG fraction was coupled to $7.5 \mathrm{ml} \mathrm{CNBr-Sepharose} 4 \mathrm{~B}$ as described earlier [22] and the beads were stored at $4^{\circ} \mathrm{C}$ with addition of preservative. The amount of protein coupled to beads was measured by estimating protein in the supernatant before and after coupling. Two ml beads were packed in a mini column and equilibrated with 20
$\mathrm{mM}$ MES $\mathrm{pH}$ 6.8. Five $\mathrm{ml}$ volumes of saliva was applied to the affinity column and equilibrated for $30 \mathrm{~min}$. The column was washed with 10 volumes of equilibration buffer. The bound enzyme was eluted with $\mathrm{Gly}-\mathrm{HCl}$ buffer $\mathrm{pH} 2.7$ and $\mathrm{pH}$ was raised immediately with $1.0 \mathrm{M}$ Tris. The fractions were further tested for the presence of enzyme by dot blotting. The enzyme activity was assayed and the purity of the enzyme was examined staining the polyacrylamide gels with silver.

\section{Results}

\section{Characterization of TPST}

The presence of tyrosylprotein sulfotransferase activity was observed in human saliva using EAY as sulfate acceptor and [35S] PAPS as sulfate donor. The clear supernatant of normal and parotid saliva showed TPST activity. The tyrosine sulfation increased proportionately with increasing concentrations of saliva protein up to 25 $\mu \mathrm{g}$ (Figure 1). The enzyme activity increased with increased incubation time up to $30 \mathrm{~min}$ and reached its maximum at $60 \mathrm{~min}$ (Figure 2). The effect of $\mathrm{pH}$ on the EAY sulfation by human whole saliva and parotid saliva are shown in Figure 3. Using the MES buffer, the $\mathrm{pH}$ optimum for the sulfation of EAY by the two enzymes was found to be 6.8 and significant activity was also observed in parotid saliva at $\mathrm{pH}$ 5.5. In the absence of $\mathrm{MnCl}_{2}$, minimal sulfation of EAY was detected. Optimum enzyme activity was detected at $20 \mathrm{mM} \mathrm{MnCl}_{2}$ (Figure 4)

The direct effect of increasing concentrations $(0.025 \%-0.25 \%)$ of Triton X-100 concentrations on the activity of tyrosylprotein sulfotransferase was studied. No change in the enzyme activity was observed at various concentrations of Triton X-100 (data not shown). Since the enzyme present in saliva was not membrane bound, tyrosylprotein sulfotransferase sulfation of EAY was not altered in the presence of detergent. Requirements of metal ions for tyrosylprotein sulfotransferase of human whole saliva is given in Table 1 . Of the metals examined at $20 \mathrm{mM}, \mathrm{Mn}^{2+}$ and $\mathrm{Ca}^{2}$ were able to stimulate tyrosylprotein sulfotransferase activity, where as $\mathrm{Mg}^{2+}$ exhibited around $50 \%$ of the stimulation attained with $\mathrm{Mn}^{2+}$ and EDTA inhibited the enzyme activity.

\section{Immunoprecipitation}

The polyclonal TPST antibodies were also tested for their ability to immunoprecipitate the TPST in the saliva. Antibodies were incubated with the saliva and coupled to protein A Sepharose beads. After centrifugation, presence of the TPST activity was determined in the supernatant by enzyme assay. As shown in Figure 5, with increasing concentration of TPST antiserum in the immunoprecipitated sample, the supernatant showed decreased TPST activity. Almost $80 \%$ of the activity was immunoprecipitated with $50 \mu \mathrm{l}$ of a 1:1000 dilution of antiserum, when compared with the preimmune serum.

\section{Purification of TPST from Human saliva}

Purification of TPST to homogeneity from saliva was achieved by immunoaffinity column chromatography. This method resulted in a 25, 071-fold increase in tyrosine sulfating activity (Table 2). The purified enzyme exhibited protein band of 50-54 kDa on SDS-PAGE (Figure 6A) and on immunoblots (Figure 6B) similar to the enzyme obtained from submandibular salivary glands [1]. The 3, 389-fold purification of tyrosine sulfating activity from human saliva to near homogeneity (Table 2 ) differs from 
the 140, 000 and 25, 358-fold purification required for adrenal and rat submandibular salivary gland enzyme, respectively, suggesting that saliva represent a better enriched source of this enzyme.

\section{Discussion}

Sulfation represents an important mechanism in vivo for the biotransformation and excretion of a variety of proteins. Upon sulfation some proteins undergo changes in their biological activities to fulfill particular biochemical and physiological needs. Since the first description of a TPST activity, the enzyme has been reported in various tissues in bovine adrenal medulla [14], rat [15], and PC12 cells [23]. However, there are no reports of its presence in secretion. In this paper, the existence of tyrosylprotein sulfotransferase activity was demonstrated in human whole saliva and parotid saliva using ${ }^{35}$ S-PAPS as cosubstrate for sulfation. Using the acidic, synthetic polymer, poly $\mathrm{Glu}_{6}, \mathrm{Ala}_{3}, \mathrm{Tyr}_{1}$ (EAY), Domiano and Roth [15] demonstrated a fairly wide-tissue distribution of tyrosylprotein sulfotransferase in the rat. Later, Sundaram [18] have characterized the enzyme present in the rat submandibular salivary glands. Some of the properties of human salivary tyrosylprotein sulfotransferase described here appear to be similar to those reported earlier for this enzyme in other rat tissues. As shown in the Figure 4, the human salivary tyrosylprotein sulfotransferase exhibited optimum $\mathrm{pH}$ at 6.8, which is similar to sulfotransferase reported in rat submandibular salivary glands [18] and other rat tissues $[15,17]$. However, the enzyme isolated from rat submandibular salivary glands displayed $\mathrm{pH}$ optimum of 6.2 [18] and the $\mathrm{pH}$ optimum observed for rat brain was 5.8 [24]. The solubilized enzyme from adrenal medulla has a pH optimum between 6.0 and 6.5 [14]. Human salivary tyrosylprotein sulfotranferase activity was stimulated by the divalent cations $\mathrm{Mn}^{2+}, \mathrm{Ca}^{2+}$ and partially by $\mathrm{Mg}^{2+}$ and was inhibited by EDTA. The enzymatic activity mediating the sulfation of proteins in PC12 cell was stimulated by the presence of $\mathrm{Mg}^{2+}$ and $\mathrm{Mn}^{2+}$ and inhibited by EDTA [14]. Both $\mathrm{Mn}^{2+}$ and $\mathrm{Mg}^{2+}$ were equally effective in activating EAY sulfation by bovine adrenal medulla [14] and rat cerebral cortex [16], where as $\mathrm{Mn}^{2+}$ and $\mathrm{Co}^{2+}$ stimulated rat liver tyrosylprotein sulfotrasferase [15]. In contrast, sulfation of an endogenous membrane protein in A431 cell was not inhibited by EDTA [25].

Antibodies raised against the tyrosylprotein sulfotransferase from rat submandibular salivary glands recognized the enzyme present in the saliva and the antibody was also capable of immunoprecipitating the enzyme activity in saliva. SDS-PAGE analysis of salivary tyrosylprotein sulfotransferase isolated from antibody column revealed a protein of 50-54 $\mathrm{kDa}$ in silver stained gels. A similar 50-54 kDa protein was observed for TPST purified from bovine adrenal medulla [26], rat liver [22] and submandibular salivary glands [1].

\section{Summary}

We have identified TPST in human saliva in addition to our earlier reports on its presence in submandibular salivary glands [1]. Although the enzyme activity responsible for tyrosine sulfation was demonstrated several decades ago, very little is known about the function of tyrosine sulfation, particularly, in salivary metabolism. The better understanding of this process needs further studies involving the identification of salivary proteins that are candidates for tyrosine sulfation. In naturally occurring substrates of tyrosylprotein sulfotransferase, the sulfated tyrosyl residues are predominantly surrounded by acidic amino acids $[27,28]$. These studies suggest that acidic environments are the important determinants for tyrosine sulfation. Salivary statherin is a 43-residue polypeptide which is tyrosinerich and contains 7 tyrosine residues. The peptide also contains a sequence E-Q-P-L-Y (residues 26-30) suggested for tyrosine sulfation $[28,29]$. The availability of TPST and antibody will facilitate well-defined studies on the role of this important function in saliva in physiological and pathological conditions.

\section{Acknowledgments}

This work was supported by grant \#AA09191 from the National Institute on Alcohol Abuse and Alcoholism.

\section{Conflict of interest}

The authors have declared that no conflict of interest exists.

\section{References}

1. William S, Ramaprasad $P$ and Kasinathan C. Purification of tyrosylprotein sulfotransferase from rat submandibular salivary glands. Arch Biochem Biophys. 1997; 338: 90-96.

2. Huttner WB and Baeuerle PA. Protein Sulfation on Tyrosine. Modern Cell Biology. 1988; 6 :97-140.

3. Mutt V. Cholecystokinin-isolation, structure and functions. In: Glass GBJ, ed. Gastrointestinal Hormones. New York: Raven Press. 1980:169.

4. Bettelheim FR. Tyrosine-O-sulphation in a peptide from fibrinogen. J Am Chem Soc. 1954; 76:2838- 22839.

5. Gregory H, Hardy P.M, Jones D.S, et al. The antral hormone gastrin. Nature 1964; 204:931-933.

6. Anastasi A, Bertaccini G, and Erspamer V. Pharmacological data on phyllokinin (bradykinyll-isoleucyl-tyrosine-O-sulphate) and bradykinyl-isoleucy-tyrosine. J Pharmacol Chemother. 1966; 27:479485.

7. Nachman R.J, Holman G.M, Cook B.J, et al. Leukosulfakinin-II, a blocked sulfated insect neuropeptide with homology to cholecystokinin and gastrin. Biochem Biophys Res commun. 1986; 140:357-364.

8. Hortin G.L, Farries T and Atkinson J.P. Sulfation of C4 (fourth component of complement): effects of $\mathrm{C} 4$ processing and activity. FASEB J. 1988; 2: A1646.

9. Stone S.R and Hofsteenge J. Kinetics of the inhibition of thrombin by Hirudin. Biochemistry 1986; 25:4622-4628.

10. Hirata T, Furukawa Y, Yang B.G et al. Human P-selectin glycoprotein ligand-1 (PSGL-1) interacts with the skin-associated chemokine CCL27 via sulfated tyrosines at the PSGL-1 amino terminus. J Biol Chem. 2004; 279:51775-1782.

11. Farzan M, Mirzabekov T, Kolchinsky P et al. Tyrosine sulfation of the amino terminus of CCR5 facilitates HIV-1 entry. Cell 1999; 96:667676.

12. Bodanszky M, Martinez J, Priestley G.P et al. Cholecystokinin (pancreozymin) 4 Synthesis and properties of a biologically active analogue of the C-terminal heptapeptide with epsilonhydroxynorleucine sulfate replacing tyrosine sulfate. J Med Chem. 1978; 21:1030-1035.

13. Baeuerle P.A and Huttner W.B. Inhibition of N-glycosylation induces tyrosine sulfation of hybridoma immunoglobuin G. EMBO J. 1984;3:2209-2215.

14. Lee R.W.H and Huttner W.B. (Glu62, Ala30, Tyr8)n serves as highaffinity substrate for tyrosylprotein sulfotransferase: A Golgi enzyme. Proc Natl Acad Sci. 1985; 82:6143-6147.

15. Domiano S.R and Roth J.A. Characterization of Tyrosylprotein Sufotransferase from Rat Liver and Other Tissues. J Biol Chem. 1989;264:899-905.

16. Vargas F and Schwartz J.C. Apparent identity of cerebral tyrosylsulfo-transferase activities using either a cholecystokinin 
derivative or an acidic amino acid polymer as substrate. FEBS LETTERS 1987; 211:234-238.

17. Kasinathan C, Sundaram P, Slomiany B.L et al. Identification of tyrosylprotein sulfotransferase in rat gastric mucosa. Enzyme 1992;46:179-187.

18. Sundaram P, Slomiany A, Slomiany B.L et al. Tyrosylprotein sulfotransferase in rat submandibular salivary glands. Int J Biochem. 1992;24:663-667.

19. Sane DC, Baker MS. Human platelets possess tyrosylprotein sulfotransferase (TPST) activity. Thromb Haemost. 1993; 69:272-275.

20. Hay D.I. Fractionation of human parotid salivary proteins and the isolation of an histidine-rich acidic peptide which shows high affinity for hydroxyapatite surfaces. Arch Oral Biol. 1975;9:553-558.

21. Laemmli U.K. Cleavage of structural proteins during the assembly of the head of bacteriophage T4. Nature 1970;227: 680-685.

22. Ramaprasad P and Kasinathan C. Isolation of tyrosylprotein sulfotransferase from liver. Gen Pharmacol. 1998; 30 :555-559.

23. Lee R.W.H and Huttner W.B. Tyrosine-O-sulfated proteins of PC12 pheochromocytoma cells and their sulfation by a tyrosylprotein sulfotransferase. J Biol Chem. 1983;258: 11326-11334.

24. Vargas F, Frerot O, Tuong M.D et al. Characterization of a tyrosine sulfotransferase in rat brain using cholecystokinin derivatives as acceptors. Biochemistry. 1985; 24:5938-5943.

25. Liu N and Baenziger J.U. In vivo and in vitro tyrosine sulfation of a membrane glycoprotein. J Biol Chem. 1986; 261: 856 - 861.

26. Niehrs $C$ and Huttner W.B. Purification and characterization of tyrosylprotein sulfotransferase. EMBO J. 1990; 9: 35-42.

27. Hortin G, Tollefsen D.M, and Strauss A.W. Identification of two sites of sulfation of human heparin cofactor II. J Biol Chem. 1986; 261:15827 - 15830.

28. Lin W.H, Larsen K, Hortin G.L et al. Recognition of substrates by tyrosylprotein sulfotransferase. Determination of affinity by acidic amino acids near the target sites. J Biol Chem 1992; 267:2876-2879.

29. Bundgaard J.R, Vuust J and Rehfeld J.F. New consensus features for tyrosine O-sulfation determined by mutational analysis. J Biol Chem 1997; 272:21700-21705.

\section{Tables \& Figures}

Table 1: Requirements for Human Salivary Tyrosylprotein Sulfotransferase Activity.

\begin{tabular}{|c|c|}
\hline Divalent cation 10 (mM) & $\begin{array}{c}\text { Tyrosylprotein Sulfotransferase } \\
\text { (pmol/mg/30 min) }\end{array}$ \\
\hline $\mathrm{MnCl} 2$ & $12.4 \pm 1.7$ \\
\hline $\mathrm{CaCl} 2$ & $9.7 \pm 1.4$ \\
\hline $\mathrm{MgCl} 2$ & $5.6 \pm 1.3$ \\
\hline EDTA & $1.9 \pm 0.7$ \\
\hline
\end{tabular}

Enzyme activities were measured as described under Materials and Methods. Values are the mean \pm SE of three experiments.

Table 2. Comparison of TPST properties

\begin{tabular}{|c|c|c|}
\hline Property & $\begin{array}{c}\text { Submandiblular salivary } \\
\text { gland TPST }\end{array}$ & Saliva TPST \\
\hline Mol. Wt (kDa) & 55 & 55 \\
\hline pH optimum & $6.2-6.8$ & 6.8 \\
\hline $\begin{array}{c}\text { Additives: } \\
\text { MnCl2 (mM) } \\
\text { Triton X-100 }\end{array}$ & $\begin{array}{c}\text { Increase in activity } \\
\text { No increase in } \\
\text { activity }\end{array}$ \\
\hline $\begin{array}{c}\text { Spec. Activity* } \\
\text { unpurified TPST }\end{array}$ & 2.1 & 12.3 \\
\hline $\begin{array}{c}\text { Spec. Activity* of } \\
\text { purified TPST }\end{array}$ & 53250 & 41670 \\
\hline Purification fold & 25358 & 3389 \\
\hline
\end{tabular}

* (pmol/mg/30 min)
Figure 1. Tyrosine sulfation activity of human whole saliva as a function of protein concentration. The tyrosylprotein sulfotransferase activity was measured as described under Materials and Methods except that the protein concentration was varied.

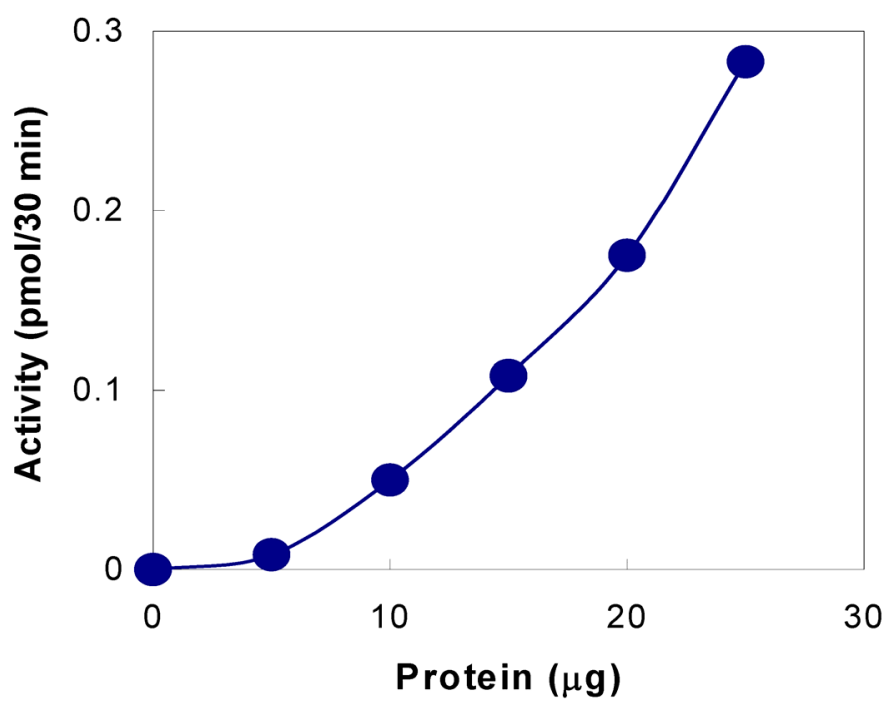

Figure 2. Tyrosine sulfation activity of human whole saliva as a function of time. The tyrosylprotein sulfotransferase activity was measured as described under Materials and Methods except that reaction time was varied.

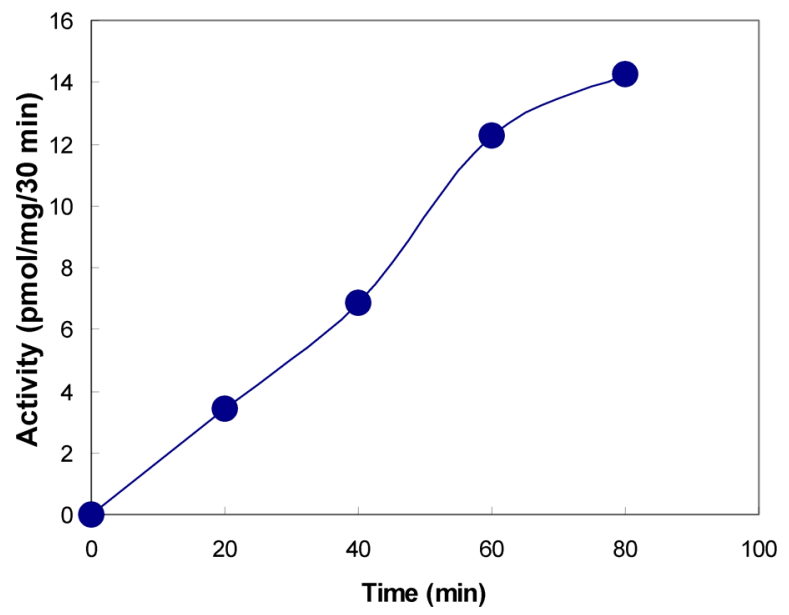

Figure 3. Effect of $\mathrm{pH}$ on the activity of tyrosylprotein sulfotransferase of human whole saliva $(\bullet)$ and parotid saliva $(\bullet)$. The tyrosylprotein sulfotransferase activity was measured as described under Materials and Methods except that the $\mathrm{pH}$ of the assay buffer was varied.

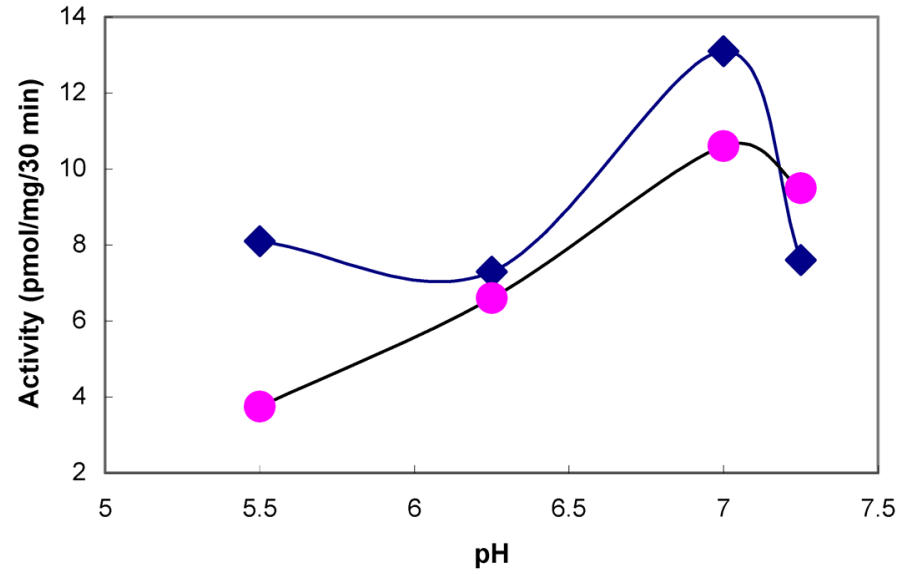


Figure 4. Effect of $\mathrm{MnCl}_{2}$ on tyrosylprotein sulfotransferase of human whole saliva. The composition of the assay medium was described under Materials and Methods except that $\mathrm{MnCl}_{2}$ concentration was varied from 0 to $30 \mathrm{mM}$.

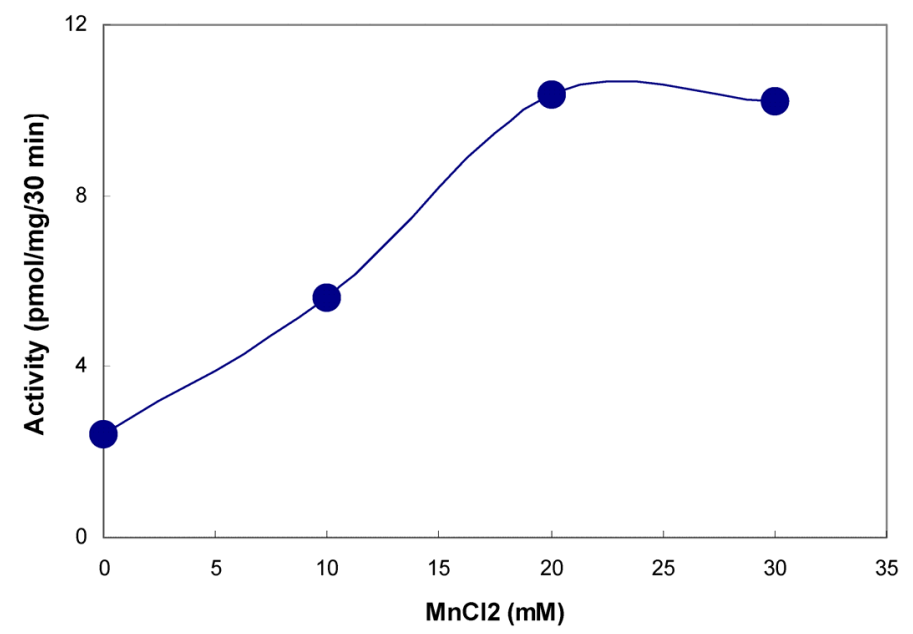

Figure 5. Immunoprecipitation with anti-TPST antiserum. The indicated amounts of anti-TPST antiserum were incubated in a final volume of $100 \mu \mathrm{l}$ with human saliva. The mixtures were further treated and the supernatants assayed for tyrosylprotein sulfotransferase activity as described under Materials and Methods.

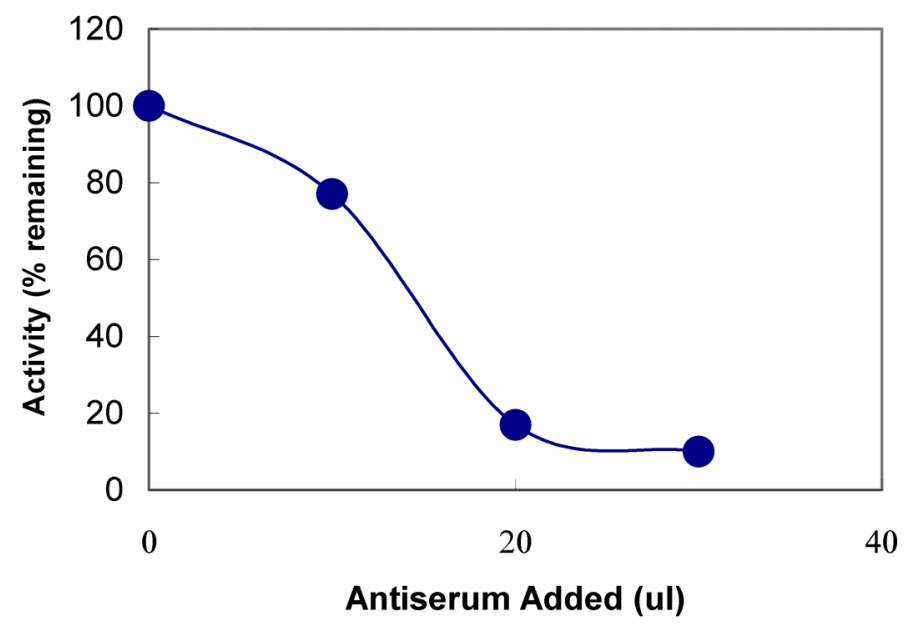

Figure 6. Western blot analysis of purified tyrosylprotein sulfotransferase. The immunoblot analysis was carried out as described under Materials and Methods. Identification of TPST purified from whole saliva by silver staining (Lane A) and by western blot (Lane B).

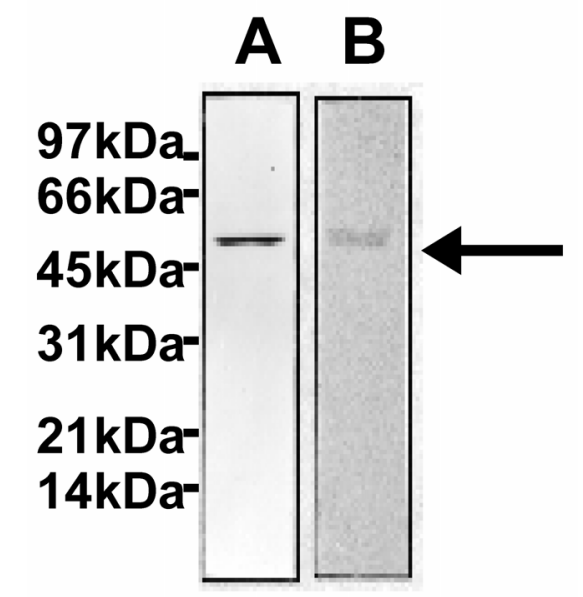

